\title{
The diagnosis of asthma in children: An evidence- based approach to a common clinical dilemma
}

R Masekela, ${ }^{1}$ PhD; S M Risenga, ${ }^{2}$ Cert Pulmonology (SA) Paed; O P Kitchin, ${ }^{3}$ Cert Pulmonology (SA) Paed;

D A White, ${ }^{4}$ Cert Pulmonology (SA) Paed; G Davis, ${ }^{5} \mathrm{MB}$ ChB; P Goussard, ${ }^{6} \mathrm{PhD}$; A I Manjra, ${ }^{7}$ FCPaed (SA), M Clin Pharm;

F E Kritzinger,,${ }^{6,8}$ Cert Pulmonology (SA) Paed; M Levin,,${ }^{9} \mathrm{PhD} ; \mathbf{H}$ Zar, ${ }^{9} \mathrm{PhD}$; R J Green, ${ }^{10} \mathrm{PhD}$, DSc; on behalf of the South African

Childhood Asthma Working Group (SACAWG)

${ }^{1}$ Inkosi Albert Luthuli Central Hospital and Department of Paediatrics and Child Health, School of Clinical Medicine, College of Health Sciences, University of KwaZulu-Natal, Durban, South Africa

${ }^{2}$ Department of Pulmonology and Allergy, Faculty of Health Sciences, Polokwane/Mankweng Campus, University of Limpopo, Polokwane, South Africa

${ }^{3}$ Private Practice, Netcare Waterfall City Hospital, Johannesburg, South Africa

${ }^{4}$ Charlotte Maxeke Academic Hospital and Department of Paediatrics and Child Health, Faculty of Health Sciences, University of the Witwatersrand, Johannesburg, South Africa

${ }^{5}$ Private Practice, Greenside, Johannesburg, South Africa

${ }^{6}$ Department of Paediatrics and Child Health, Faculty of Medicine and Health Sciences, Stellenbosch University, Cape Town, South Africa

${ }^{7}$ Private Practice, Life Westville Hospital, Durban, South Africa

${ }^{8}$ Netcare Christiaan Barnard Memorial Hospital, Cape Town, South Africa

${ }^{9}$ Department of Paediatrics and Child Health, Red Cross War Memorial Children's Hospital, and Medical Research Council Unit on Child and Adolescent Health, Faculty of Health Sciences, University of Cape Town, South Africa

${ }^{10}$ Steve Biko Academic Hospital and Department of Paediatrics and Child Health, School of Medicine, Faculty of Health Sciences, University of Pretoria, South Africa

Corresponding author: R Masekela (masekelar@ukzn.ac.za)

Background. Asthma is a heterogeneous condition characterised by chronic inflammation and variable expiratory airflow limitation, as well as airway reversibility. The diagnosis of asthma in young children is limited by the inability to perform objective lung function testing in this group of patients and the wide variety of conditions that can phenotypically present with asthma-like symptoms.

Objectives. To provide an evidence-based approach for clinicians to accurately diagnose asthma in young children and to assess the level of control to guide therapeutic decisions.

Methods. The South African Childhood Asthma Working Group (SACAWG) convened in January 2017 with task groups, each headed by a section leader, constituting the editorial committee on assessment of asthma epidemiology, diagnosis, control, treatments, novel treatments and self-management plans. The asthma diagnosis and control task groups reviewed the available scientific literature and assigned evidence according to the Grades of Recommendation Assessment, Development and Evaluation (GRADE) system, providing recommendations based on current evidence.

Conclusions. Asthma in young children should only be diagnosed if all other causes of wheezing have been considered and excluded, and if there is a response to a therapeutic trial and worsening with withdrawal of asthma medication. Asthma control should be assessed at each visit to guide therapeutic decisions.

S Afr Med J 2018;108(7):540-545. DOI:10.7196/SAMJ.2018.v108i7.13165

On a global scale, asthma is the most common chronic non-communicable disease in children. It is a heterogeneous condition characterised by chronic inflammation and variable expiratory airflow limitation, ${ }^{[1]}$ as well as airway reversibility (evidence level C). Airway inflammation and airway obstruction are features of asthma and are usually not measured in young children, except in research settings. The term asthma, therefore, should not be used to describe preschool wheezing illness. ${ }^{[2]}$ The child should demonstrate clinical improvement during 2 - 3 months of controller treatment, with worsening of symptoms after treatment cessation. ${ }^{[3]}$ A history of other allergic disease (eczema or allergic rhinitis) or asthma in firstdegree relatives is useful in some instances (evidence level B).

\section{Objectives}

We reviewed the current literature on the diagnosis of asthma in children, with particular emphasis on young children and the available evidence. We also examined the assessment of asthma control in children and the current evidence basis for the importance of these assessments.

\section{Methods}

The South African Childhood Asthma Working Group (SACAWG) convened in January 2017 with six task groups, each assigned to a section leader (Appendix A), who constituted the editorial committee on assessment of asthma epidemiology, diagnosis, control, treatments, novel treatments and self-management plans. The task groups reviewed the available scientific literature on the diagnosis of asthma and assessment of asthma control in young children according to high-quality evidence, graded the level of evidence, and made recommendations based on the literature (Appendix B). 


\section{Asthma in children}

The presentation and differential diagnosis of asthma differ significantly as the child matures. For the purpose of this review and in line with the current literature, children are categorised as preschoolers $(<5$ years of age) and older children.

\section{Children $<5$ years of age}

One-third of all children wheeze at least once before their third birthday. Children $<5$ years old are prone to frequently recurring viral upper-respiratory tract infections, which may be associated with wheeze. Although wheeze commonly occurs, most children are asymptomatic by school-going age, with only one-quarter having persistent symptoms and later developing asthma ${ }^{[2]}$ (evidence level B). In South Africa (SA), wheeze and asthma need to be distinguished from other causes of pneumonia, e.g. tuberculosis and other bacterial pneumonias (Table 1).

\section{Predictive indices for asthma}

As asthma in infancy and preschoolers has nonspecific symptoms, making it difficult to determine who has or will have asthma, predictive models have been developed. ${ }^{[4]}$ These models have been proposed to improve early diagnosis, and therefore early access to treatment. ${ }^{[5]}$ Some of the predictive models are the modified asthma predictive index (mAPI) and the prevention and incidence of asthma and mite allergy (PIAMA) risk score (evidence level C). ${ }^{[5,6]}$ Use of these scores has not been validated in the African setting, where the atopy levels are lower (evidence level C), and should therefore not be used in the SA context.

\section{History}

History-taking alone is often all that is needed to diagnose a preschool wheezing disorder. Rather than categorising the wheezy 'phenotype' of the child, the decision to initiate an asthma therapeutic trial should primarily be determined by the following:

- Severity of wheezy episodes (presence of dyspnoea, increased respiratory rate and need for oxygen therapy during the episode).
- Frequency of wheezy episodes (the child is symptomatic for $>10$ days during upper-respiratory tract infections or has $>3$ wheezy episodes per year).

- Temporal pattern of symptoms (presence of wheezing not only with viral colds (infections), but triggered by allergens, irritants (pollution), exercise and sudden emotional changes (crying or laughing) between episodes (evidence level C) or worsening of symptoms on most days and nights).

- Reversibility of wheezy episodes (bronchodilator response test (evidence level D)).

- A positive family history of eczema (allergic dermatitis), allergic rhinitis, allergic conjunctivitis and/or food allergy (evidence level B).

- History of an individual child's allergic problems, as mentioned above.

\section{Clinical examination}

This may be unhelpful in the young child, especially where there are no other atopic manifestations, but it must be remembered that 'not all that wheezes is asthma'

\section{Therapeutic trial}

The current evidence based on symptoms and their relationship to asthma diagnosis in under-5 children are set out in Table 2 . The principle when starting treatment for a child with a wheezing disorder is that treatment should be viewed as a therapeutic trial, i.e. therapy should be initiated and the child followed up after $6-8$ weeks (Fig. 1). ${ }^{[1,7,8]}$ If there is no clinical response to therapy, it should be discontinued and a differential diagnosis considered as the cause of wheezing (Table 1). Should the child respond to therapy after the trial, medication should be discontinued. The reasons for a therapeutic response may be owing to the child being asthmatic or the natural history of improvement in the case of viral infections. Should symptoms recur after withdrawal of therapy, the child can be placed on maintenance therapy. ${ }^{[7,8]}$

Early use of inhaled corticosteroids (ICSs) in preschool children with wheeze, reduces symptoms and prevents or delays the onset of

Table 1. Differential diagnosis of wheeze in children $<5$ years of age ${ }^{\star}$

\begin{tabular}{|c|c|}
\hline Category & Disease entity \\
\hline \multirow[t]{5}{*}{ Congenital upper airway } & Complete tracheal rings \\
\hline & Tracheomalacia \\
\hline & Laryngomalacia \\
\hline & Vocal cord palsy/paresis \\
\hline & Subglottic stenosis/post-intubation/ congenital \\
\hline \multirow[t]{2}{*}{ Congenital lower airway } & Vascular rings/slings \\
\hline & Bronchomalacia \\
\hline \multirow[t]{4}{*}{ Aspiration } & Gastroesophageal reflux disease \\
\hline & Swallowing inco-ordination \\
\hline & Laryngeal cleft \\
\hline & Tracheo-oesophageal fistula \\
\hline \multirow[t]{5}{*}{ Bronchiectasis } & Cystic fibrosis \\
\hline & Primary ciliary dyskinesia \\
\hline & Persistent bacterial bronchitis \\
\hline & Primary immunodeficiency \\
\hline & HIV \\
\hline \multirow[t]{3}{*}{ Endobronchial lesions } & Foreign body \\
\hline & Tuberculosis granuloma \\
\hline & Malignancies \\
\hline \multirow[t]{2}{*}{ Cardiac } & Enlarged heart \\
\hline & Congenital heart disease (left-to-right shunts) \\
\hline
\end{tabular}


Table 2. Diagnostic characteristics of asthma in children $<5$ years of age and grade of recommendation ${ }^{*}$

Characteristics
Nocturnal coughing (problematic, with awakening)
Symptoms persisting in children $>3$ years old
Response to a bronchodilator (short-acting beta-agonist)
No seasonal variation in symptoms
Viral colds with accompanying chest involvement
Symptoms with specific trigger exposure, including emotional upsets (e.g. crying and laughing)
Response to a short course of oral corticosteroids during acute exacerbation of symptoms
Comorbid allergic rhinitis, proven food allergy and atopic dermatitis
Absence of seasonal variation
Wheezing lasting $>1$ month
A positive modified bronchodilator test
${ }^{*}$ Adapted from Global Initiative for Asthma. ${ }^{[1]}$

Table 3. Differential diagnosis of asthma in children 6 - 11 years of age ${ }^{\star}$

\begin{tabular}{ll}
\hline Condition & Symptoms \\
\hline Chronic upper-airway cough syndrome & Sneezing, itching, blocked nose, throat clearing \\
Inhaled foreign body & Sudden onset of symptoms, unilateral wheeze \\
Bronchiectasis & Recurrent infections, productive cough \\
Primary ciliary dyskinesia & Recurrent infections, productive cough, sinusitis \\
Congenital heart disease & Cardiac murmurs \\
Bronchopulmonary dysplasia & Preterm delivery, symptoms since birth \\
Cystic fibrosis & Excessive cough and mucus production, gastrointestinal symptoms \\
${ }^{*}$ Adapted from Global Initiative for Asthma. ${ }^{[1]}$ &
\end{tabular}

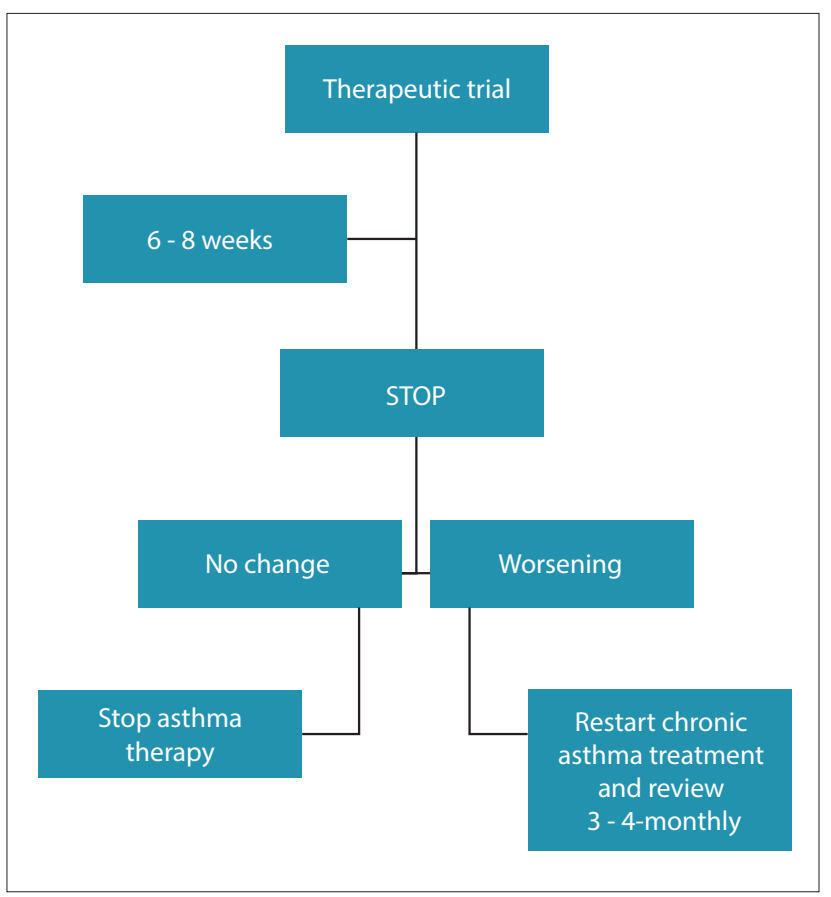

Fig. 1. Therapeutic trial and review protocol for young children with suspected asthma.

asthma in children (evidence level A) ${ }^{[9-11]}$ Therefore, early institution of therapy will not improve lung function of those who do not have asthma.

There are specific clinical pointers, which should guide the healthcare practitioner to seek another diagnosis in children with persistent wheezing (Box 1).
Box 1. Clinical signs in children $<5$ years of age, suggesting an alternative diagnosis and a need for specialist referral

Failure to thrive

Continuous wheezing without a clear history of exacerbation

Digital clubbing

Failure to respond to 2 - 3 months' optimal asthma treatment

(e.g. correct technique, compliance)

Vomiting associated with respiratory symptoms

Very young age of onset of respiratory symptoms (often during the first month of life)

Severe hypoxaemia at clinical presentation

Focal/segmental lung signs

Cardiovascular signs

\section{Children 6 - 11 years of age}

For children $\geq 6$ years of age, besides the presenting symptoms, variable airflow limitation can be demonstrated by objective testing on peak flow measurements or by spirometry (Box 2) - ideally before commencement of controller medication. Normal lung function tests do not exclude the diagnosis of asthma (evidence level B). ${ }^{[12]}$ Where the history is suggestive of asthma with normal spirometry, other specialised tests, such as methacholine challenge and exercise challenge tests, may be done by a pulmonologist to confirm the diagnosis (Appendix C).

If the respiratory symptoms are suggestive of asthma, but not confirmed by variable airflow limitation or resolution with commencement of therapy, an alternative diagnosis is usually sought and may include those listed in Table 3. Some of these conditions may coexist with asthma. Investigations that are not helpful in diagnosing asthma include chest radiography, which may be normal or show evidence of air trapping with hyperinflation. 
Box 2. Confirmation of variable airflow limitation and grade of recommendation

Pulmonary function test $\quad$ Grade

\begin{tabular}{ll}
\hline Reduced $\mathrm{FEV}_{1} / \mathrm{FVC}$ (normal $>0.9$ ) when $\mathrm{FEV}_{1}$ is low & $\mathrm{A}$
\end{tabular}

Positive bronchodilator reversibility test with an increase in $\mathrm{FEV}_{1}$ of $>12 \%$ predicted

Positive exercise challenge test with a fall in $\mathrm{FEV}_{1}$ of $>12 \%$ predicted or PEF $>15 \%$, target heart rate $(0.8 \times 220$ - age in years $)$ and A noting that target heart rate can be reached earlier in children

PEF variability 2 weeks twice a day, with an average daily diurnal PEF variability of $>13 \%$

Excessive variation of pulmonary function between outpatient visits with variability of $\mathrm{FEV}_{1}>12 \%$ or $\mathrm{PEF}>15 \%$ (using the same peak flow meter during each visit) with or without respiratory tract infections

$\mathrm{FEV}_{1}=$ forced expiratory volume in 1 second; $\mathrm{PEF}=$ peak expiratory flow.

\section{Box 3. Recommendations to achieve asthma control and level of evidence}

\begin{tabular}{ll}
\hline Recommendations & $\begin{array}{c}\text { Level of } \\
\text { evidence }\end{array}$ \\
\hline $\begin{array}{l}\text { Once an asthmatic is on controller therapy, regular assessment of control is critical. Of equal importance is regular } \\
\text { assessment of future risk (exacerbations and side-effects) }\end{array}$ & A \\
Control must be formally measured at every visit and not fewer than 6-monthly & B \\
Formal tools for assessing control include symptom assessments, scores (such as the cACT and ACQ) and spirometry & B \\
$\begin{array}{l}\text { For uncontrolled asthma in children }>5 \text { years old using a low-dose ICS, doubling the dose of ICS is as beneficial as adding } \\
\text { a LABA }\end{array}$ & A \\
Where ICSs cause local or systemic side-effects or there is a risk of such side-effects, LABA addition is preferred for poorly & C \\
controlled asthma in children $>5$ years of age & B \\
$\begin{array}{l}\text { In more severe asthma, before the dose of ICS is increased or a new drug is added, it is critical to assess the reasons for } \\
\text { poor control thoroughly, including reconsidering the diagnosis, educating patients and treating comorbidities }\end{array}$ & C \\
LABA use has not been well studied in preschool children and efficacy and safety are not established. LABAs should not be \\
used in these children
\end{tabular}

Table 4. Assessment of asthma control and future risk in children $<5$ years of age (evidence level B) ${ }^{*}$

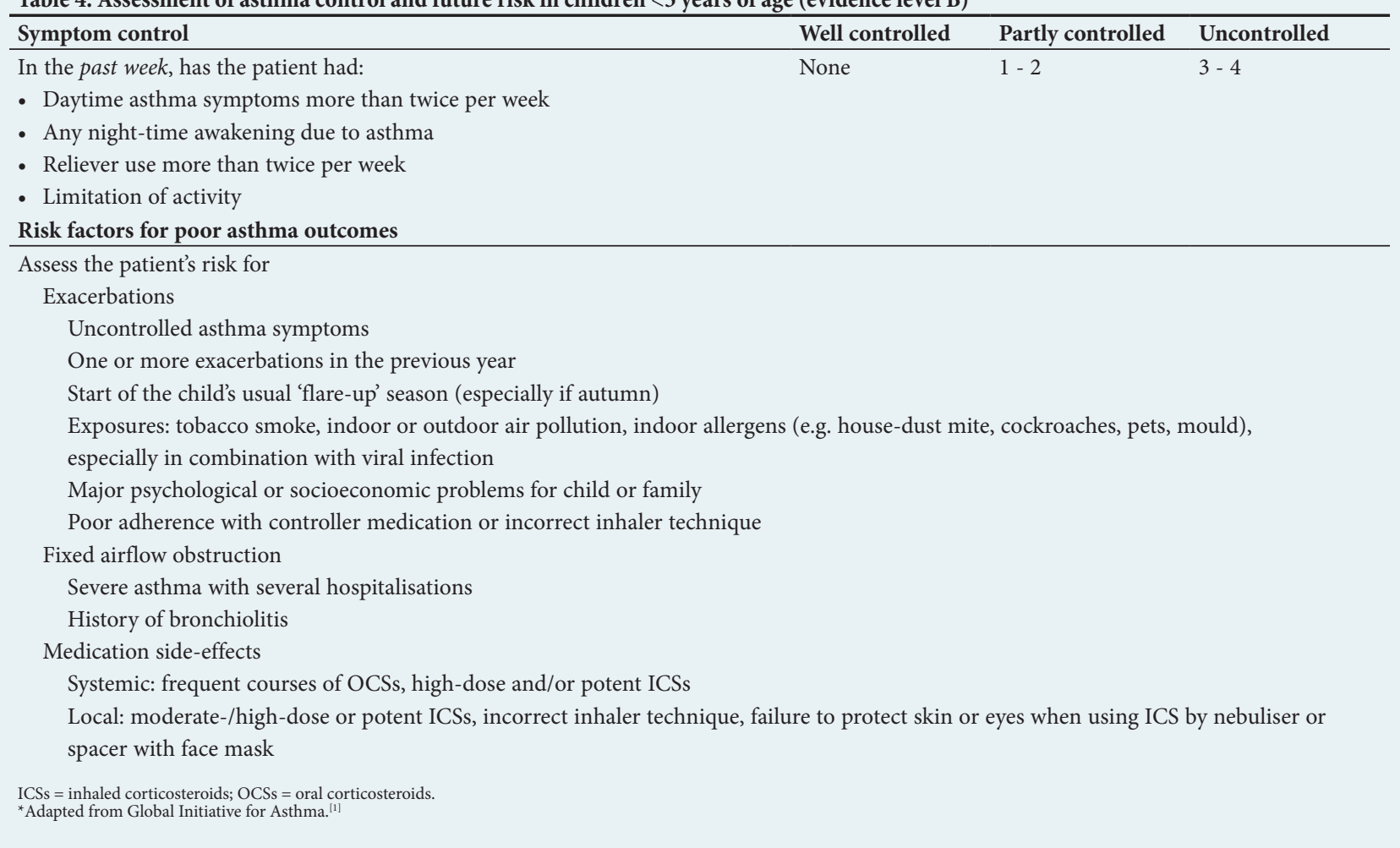




\section{Predictors of asthma in childhood}

Factors that independently predict asthma in late childhood are male sex, post-term delivery, medium or low parental education, family history of asthma and/or other atopic diseases, frequency of wheeze and wheezing dyspnoea (not associated with a cold). ${ }^{[5]}$

\section{Asthma control}

Asthma control is the extent to which asthma symptoms can be observed in a patient or have been reduced or eliminated by treatment. ${ }^{[1]}$ The recent Global Initiative for Asthma (GINA) guidelines suggest that the monitoring of asthma control is essential in all asthmatics. ${ }^{[1]}$ Assessment of control should evaluate symptoms (over the past week and month) and quality of life. The risk of future exacerbations (as measured by spirometry and, possibly, exhaled nitric oxide) and medication side-effects (as a result of steroid use and, particularly, growth in children) must be assessed regularly. Optimal formal tools for assessing control offer the best insight into asthma control. ${ }^{[13]}$ No test is a gold standard and all tests must be used in conjunction to assess control (evidence level B). ${ }^{[14]}$ Every practitioner and all children $>6$ years of age should have access to a peak flow meter to assess changes in lung function.

Asthma control is significantly more likely in patients or parents/ caregivers who are educated (know their disease), are regularly taught to use the inhaler device, have a written action plan and educational material (www.asthmasa.co.za) and are encouraged to use controller medication regularly (level I evidence). If control is suboptimal, determine the reasons and educate the patient. A small number of patients need adjustment of their treatment (Box 3).

The child should demonstrate clinical improvement during the 2 3 months of controller treatment, with worsening of symptoms after treatment cessation (Fig. 1). Thereafter, assessment of asthma control and future risk can be determined at each visit (Table 4).

\section{Conclusion}

Asthma in young children should only be diagnosed when all other causes of wheezing have been considered and excluded, more so in younger children. A therapeutic trial should be performed in uncertain cases, with follow-up and withdrawal of therapy to confirm or exclude the diagnosis of asthma. Asthma control should be assessed at each visit to guide therapeutic decisions.

Acknowledgements. We acknowledge the hard work and contribution of the South African Childhood Asthma Working Group (SACAWG) members. We also acknowledge the huge contribution of the late Prof. Cas Motala, who was convener of the past three SACAWG guidelines.

Author contributions. RM: methodology, review, write-up and manuscript editing; SMR: conceptualisation, write-up and manuscript editing; OPK, DA, HZ, GD: conceptualisation, methodology, write-up and manuscript editing; ML, RJG, AIM, FEK: write-up and manuscript editing; and PG: conceptualisation, methodology, write-up.

Funding. SACAWG conducted a workshop that received an unconditional educational grant from the Allergy Society of South Africa - funded by Novartis.

Conflicts of interest. None.
1. Global Initiative for Asthma. 2017. www.ginasthma.org (accessed 22 January 2017)

2. Brand PLP, Baraldi E, Bisgaard H, et al. Definition, assessment and treatment of wheezing disorder in preschool children: An evidence-based approach. Eur Respir J 2008;32:1096-1110. https://doi.

in preschool children: An evidence-based approach. Eur Respir J 2008;32:1096-1110. https://doi.
org/10.1183/09031936.00002108
3. White D, Masekela R. Recurrent wheeze in a child under five year of age. In: Manjra A, Levin M, Gray C, eds. ALLSA Handbook of Practical Allergy. 4th ed. Cape Town: ALLSA, 2018.

4. Martinez FD, Wright AL, Taussig LM, Holberg CJ, Halonen M, Morgan WJ. Asthma and wheezing in the first six years of life. N Engl J Med 1995;332(3):133-138. https://doi.org/10.1056/NEJM199501193320301 . Castro-Rodriguez JA. The asthma predictive index: A very useful tool for predicting asthma in young children. J Allergy Clin Immunol 2010;126(2):212-216. https://doi.org/10.1016/j.jaci.2010.06.032

6. Hafkamp-de Groen E, Lingsma HF, Caudri D, et al. Predicting asthma in preschool children with asthma-like symptoms: Validating and updating the PIAMA risk score. J Allergy Clin Immuno 2013;132:1303-1310. https://doi.org/10.1016/j.jaci.2013.07.007

7. Brand PLP, Caudri D, Eber E, et al. Classification and pharmacological treatment of preschool wheezing. Changes since 2008. Eur Respir J 2014;43(4):1172-1177. https://doi.org/10.1183/09031936.00199913

. Bush A, Ngakumar P. Preschool wheezing phenotypes. Eur Med J 2016;1(1):93-101.

9. Bisgaard H, Hermansen MN, Loland L, Halkjaer LB, Buchvald F. Intermittent inhaled corticosteroids

Bisgaard H, Hermansen MN, Loland L, Halkjaer LB, Buchvald F. Intermittent inhaled corticosteroids
in infants with episodic wheezing. N Engl J Med 2006;354(19):1998-2005. https://doi.org/10.1056/ in infants with epso

10. Guilbert T, Morgan WJ, Zeiger RS, et al. Long-term inhaled corticosteroids in preschool children at high risk for asthma. N Engl J Med 2006;354(19):1985-1997. https://doi.org/10.1056/NEJMoa051378

11. The Childhood Asthma Management Program Research Group. Long-term effects of budesonide or nedocromil in children with asthma. N Engl J Med 2000;343(15):1054-1063. https://doi.org/10.1056 NEJM200010123431501

12. Galant SP, Morphew T, Newcomb RL, Hioe K, Guijon O, Liao O. The relationship of the bronchodilato response to poor asthma control in children with normal spirometry. J Pediatr 2011;158(6):953-958 https://doi.org/10.1016/j.jpeds.2010.11.029

3. Deschildre A, Pin I, El Abd K, et al. Asthma control assessment in a pediatric population: Comparison between GINA/NAEPP guidelines, childhood asthma control test (C-ACT), and physician's rating. Allergy 2014;69(6):784-790. https://doi.org/10.1111/all.12402

14. Green RJ, Klein M, Becker P, et al. Disagreement between common measures of asthma control. CHEST 2013;143:117-122. https://doi.org/10.1378/chest.12-1070

Accepted 7 May 2018.

\section{Appendix A. The SA Childhood}

Asthma Working Group (SACAWG)

Epidemiology: H Zar (leader), Western Cape; C Gray, Western Cape.

Diagnosis of asthma: R Masekela (leader), KwaZulu-Natal; S M Risenga, Limpopo; O P Kitchin, Gauteng; P Goussard, Western Cape.

Assessment of asthma control: R J Green (leader), Gauteng; D White, Gauteng; G Davis, Gauteng.

Pharmacotherapy: F E Kritzinger (leader), Western Cape; A Jeevanathrum, Gauteng; P de Waal, Free State; S Kling, Western Cape; A Vanker, Western Cape; T C Gray, Western Cape; J Morrison, Western Cape; A Puterman, Western Cape; E Zollner, Western Cape; D Rhode, Western Cape.

Pharmacotherapy - other therapies: A I Manjra (leader), KwaZuluNatal; P M Jeena, KwaZulu-Natal; V Naidoo, KwaZulu-Natal; M Annamalai, KwaZulu-Natal; A van Niekerk, Gauteng.

Self-management plans: M Levin (leader), Western Cape; S Emanuel, Western Cape; D Hawarden, Western Cape; H Katz, Gauteng.

\section{Appendix B. Level of evidence}

IA Evidence from meta-analysis and randomised controlled trials IB Evidence from at least one randomised controlled trial

IIA Evidence from at least one controlled trial without randomisation IIB Evidence from at least one or other quasi-experimental study

III Evidence from non-experimental descriptive studies, such as comparative studies, correlation studies and case-controlled studies

IV Evidence from expert committee reports, opinions or clinical experience of respected authorities 


\begin{tabular}{lll}
\multicolumn{2}{l}{ Appendix B. Grades of Recommendation Assessment, Development and Evaluation (GRADE) } \\
\hline Level of recommendation & Quality of evidence & Definition \\
\hline A & High & $\begin{array}{l}\text { High-quality research very unlikely to change our confidence in the estimate effect based } \\
\text { on level I evidence } \\
\text { B }\end{array}$ \\
Loderate & $\begin{array}{l}\text { Moderate-quality evidence, where future research is likely to have an important impact } \\
\text { on our confidence in the estimate effect. Based on level II evidence or extrapolated from } \\
\text { recommendations from level I evidence } \\
\text { Low-quality evidence, where future research is likely to have an important impact on our } \\
\text { confidence in the estimate effect. Based on level III evidence or recommendations from } \\
\text { level I and II evidence } \\
\text { Very-low-quality evidence, where the estimate effect is uncertain. Based on level IV } \\
\text { evidence or recommendations from level I, II and III evidence }\end{array}$
\end{tabular}

\begin{tabular}{|c|c|c|c|}
\hline Lung function test & Advantages & Disadvantages & Level of evidence \\
\hline Peak flow & $\begin{array}{l}\text { Cheap } \\
\text { Easy-to-teach technique } \\
\text { Pre-diagnosis and disease monitoring for older patients }\end{array}$ & Not reliable in young children & II \\
\hline Spirometry & $\begin{array}{l}\text { Computer incentive-based devices can obtain reliable } \\
\text { tests in } 2 \text { - 6-year-olds } \\
\text { Available at most centres } \\
\text { Assess reversibility to bronchodilator }\end{array}$ & $\begin{array}{l}\mathrm{FEV}_{1} 0.5 \text { and } \mathrm{FEV}_{1} 0.75 \text { may be more } \\
\text { reliable in preschoolers } \\
\mathrm{FEV}_{1} 0.5 \text { an } \mathrm{FEV}_{1} 0.75 \text { (not validated for } \\
\text { clinical application) } \\
\text { Needs active co-operation and breath } \\
\text { control }\end{array}$ & I \\
\hline Bronchial responsiveness & $\begin{array}{l}\text { Successful in preschoolers and differentiates between } \\
\text { chronic asthma and chronic coughing } \\
\text { Facilitates diagnosis of asthma }\end{array}$ & $\begin{array}{l}\text { Currently no recommendations for } \\
\text { cold air challenge testing }\end{array}$ & II \\
\hline
\end{tabular}

